\title{
Map Symbols in Video Games: the Example of "Valheim"
}

\author{
Tymoteusz Horbiński ${ }^{1}\left[\right.$ ] Krzysztof Zagata ${ }^{1} \mathbb{C}$
}

Received: 15 July 2021 / Accepted: 20 August 2021 / Published online: 13 September 2021

(c) The Author(s) 2021

\begin{abstract}
The main focus of this article is to examine the interpretation of twelve cartographic symbols on the map in Valheim. The authors set the research goal: to investigate how players and non-players interpret the symbols. The Valheim video game, which was released in 2021, is a survival game set in an open world. The authors noticed that game developers did not provide a direct explanation of the map symbols used, which could result in a different interpretation and experience of the game. The authors adopted a survey on the LimeSurvey platform as research methodology. This survey tool was used to gather information on experiences and interpretations of map symbols among a diverse group of respondents. Using online forums allowed one to disseminate the survey to a large audience of players from all over the world. Then, using the categorisation method for individual questions, a large database of respondents' answers was created. Through the analysis, the authors checked the interpretation of symbols and presented the results in the form of graphs. Then, using statistical tests, they analysed the relationship between individual symbols. The study reveals that there are intergroup differences in responses to symbols directly related to the game. With more complicated symbols that did not emphasise an unambiguous answer, both groups of respondents had a problem with indicating the meaning of the symbol. For future research, it is worth continuing research on the interpretation of various map symbols not only in games, but also in all cartographic products.
\end{abstract}

Keywords Cartography in video games $\cdot$ Symbology $\cdot$ Gamefication $\cdot$ Valheim $\cdot$ Map symbols

\section{Kartensignaturen in Videospielen am Beispiel “Valheim”}

\section{Zusammenfassung}

Das Hauptaugenmerk dieses Artikels liegt auf der Untersuchung der Interpretation von zwölf kartographischen Signaturen auf der Karte in Valheim. Die Autoren setzen das Forschungsziel, zu untersuchen, wie Spieler und Nicht-Spieler die Signaturen interpretieren. Das 2021 veröffentlichte Valheim-Videospiel ist ein Survival-Spiel, das in einer 'offenen Welt' stattfindet. Die Autoren stellten fest, dass die Spieleentwickler die verwendeten Kartensignaturen nicht direkt erklärten, was zu einer anderen Interpretation und Erfahrung des Spiels führen könnte. Als Forschungsmethodik haben die Autoren eine Umfrage auf der LimeSurvey-Plattform übernommen. Dieses Erhebungsinstrument wurde verwendet, um Informationen über Erfahrungen und Interpretationen von Kartensignaturen bei einer unterschiedlichen Gruppe von Befragten zu sammeln. Die Verwendung von Online-Foren ermöglichte es, die Umfrage an ein großes Publikum von Spielern aus der ganzen Welt zu verteilen. Anschließend wurde mit Hilfe der Kategorisierungsmethode für einzelne Fragen eine große Datenbank mit Antworten der Befragten erstellt. Durch die Analyse überprüften die Autoren die Interpretation von Signaturen und präsentierten die Ergebnisse in Form von Grafiken. Anschließend analysierten sie mit statistischen Tests die Beziehung zwischen einzelnen Signaturen. Die Studie zeigt, dass es Unterschiede zwischen den Gruppen bei der Reaktion auf Signaturen gibt, die direkt mit dem Spiel zusammenhängen. Bei komplizierteren Signaturen, die keine eindeutige Antwort betonten, hatten beide Befragtengruppen das Problem, die Bedeutung der Signature zu benennen. Für zukünftige Forschungsarbeiten lohnt es sich, die Interpretation verschiedener Kartensignaturen nicht nur in Spielen, sondern auch in allen kartografischen Produkten weiter zu beforschen.

Tymoteusz Horbiński

tymoteusz.horbinski@amu.edu.pl

1 Department of Cartography and Geomatics, Adam

Mickiewicz University in Poznań, Poznan, Poland 


\section{Introduction}

A commercial use of cartography is observable at every step, from map applications that facilitate car navigation (Horbiński et al. 2020), AR games, such as Pokémon GO or Harry Potter: Wizards Unite to VR games, such as Beat Saber or Half-life: Alyx. Such employment of cartography speeded up the technological advance that resulted in the decrease in the importance of analogue products and boosted the increase in the value of virtual products (Werner 2017). The video games industry is one of the sectors of the economy, in which cartography has developed significantly. Although this process has not echoed in the academia, it offers a wide range of opportunities to be used for academic purposes.

Hendrikx et al. (2012) believe that the game environment is presented as a $1 \mathrm{D}, 2 \mathrm{D}$, or a $3 \mathrm{D}$ area, on which the elements related to the game are placed according to the previously set layout. To operate in such space better, many producers include different maps in the game. Hendrikx et al. (2012) distinguish two types of maps: indoor and outdoor maps. Outdoor maps depict the structure and relative layout of the indoor space, usually some buildings or caves. On the other hand, outdoor maps describe the outdoor world of the game. The authors of this distinction note that the division is getting more and more blurred as new games are constantly being launched. Currently, in the world of video games there is no clear-cut distinction between games set inside a building and those set outside of it; however, when it comes to maps in games, the distinction still applies.

In video games, a map is usually a simplified depiction of the virtual world, such as in the Civilization series or a separate product, thanks to which a player may get oriented in the space of the game, such as in the GTA series. Thanks to the employment of the so-called fog, the player on the map may answer three crucial questions: Where am I?, usually signalised by the unique symbol, Where have I already been?, signalised by the area not outside of fog, and Where else may I go?, signalised by the area covered by fog. Usually, apart from fog, map symbols play the essential part on the map, just as when searching for one's position on the map. Symbols on the map inform players about crucial spots, tasks to be completed or enemies. They are crucial to the game, signalling important places related to the main game plot or subplots.

Valheim, a game produced by the Iron Gate Studio, is one of the most popular titles that was released in early February 2021 (almost 4 million accesses to the game in 20 days on the Steam platform-https://steamcommunity.com/games/ 892970/announcements/detail/3058478454611894476). It is a survival game set in the world inspired by Norse mythology with a sandbox. The player plays a part of a warrior that reaches Valheim and fights to win favour with gods to be able to finally go to the longed-for Valhalla. The game is equipped with the basic user interface that includes the map of the game's world. The map is a simple product, encompasses the designed draft of the game's world and 12 symbols. Despite the game dedicated by the creators for the PC platform, in its entire structure and programming environment, the game has the potential to reach a larger audience for AR and VR platforms. AR and VR products nowadays show simple gameplay mechanics and a limited variety of high-quality content due to the hardware capabilities and the difficulty of using the player's mobility. The Valheim game is based on low-resolution textures and low-polygonal models, which makes it possible to expand the game on AR and VR platforms. Game lovers create and update the "VHVR" modification on an ongoing basis, which enables Open VR support in full stereoscopic 3D (https://www.nexusmods. com/valheim/mods/847).

The production has been gaining enormous popularity. Despite so many fans, it is difficult to find direct explanations to all the symbols used in Valheim. Hence, the authors decided to examine how gamers interpret the symbols that occur on the map in Valheim and also to search for the answers to the following questions:

- How do gamers (Valheim players) interpret the symbols used on the map in the game?

- How do people, who have never played the game before, interpret these symbols?

\section{Related Work}

When looking at the map in the game or using a map app on the smartphone, we "can see symbols laid out in space". We expect them to refer to geographical space (Eide 2016) or to space related to the virtual game. Each map allows one to make a reference to phenomena or spatial actions from the point of view that goes beyond direct experience (Keates 1996), which allows players to imagine both close and distant events that await them as the game unfolds and they discover game's space.

Maps are a form of communication, a way of comprehending, articulating, and constructing the human world (Harley 2009). Elements of each map are, in fact, independently linked symbols with references established by convention, not one fixed, clear-cut point of reference (Langer 1953; Bertin 1974). Thus, the process of map creation needs to be based on particularly conscious choices and well thought-out decisions, because the variety of available methods and visual variables used for presenting data allows one to obtain diametrically opposed results based on one data set (Thompson et al. 2015). 
Map symbols carry information by means of visual variables that were first introduced by Bertin (1983). He identified seven categories of variables: shape, size, colour, value, orientation, texture and position. Other cartographers suggested including extra variables, i.e. chromaticity, transparency, clarity, and definition (MacEachren 1995). Psychologists examined also visual variables of objects and introduced several other ways of organising them. For instance, Kosslyn and Koenig (1992) classified variables as properties of the object (e. g. colour, texture, shape) and spatial properties (e. g. size, orientation). Different visual variables have different opportunities and serve different purposes in terms of data visualisation.

Bertin's (1983) classification of visual variables was based on whether or not they were "selective", for instance, the colour was selective, because it allowed the eye to isolate all elements in one category and ignore other categories. However, the eye cannot do the same for shape; therefore, shape is not a selective variable. Colour is also the most effective variable when one needs to find the most uniquely characterised symbol (Lloyd 1997). This type of visual search was widely studied in cognitive psychology and models describing human mechanisms of visual search were built (np. Treisman and Gelade 1980; Wolfe 2007). On the basis of multiple visual search studies Wolf and Horowitz (2004) classified visual attributes according to their ability to direct attention, including colour, size, orientation, and motion in the best, "undoubted" category. They included such variables as shape in the second best, "probable" category (Korpi et al. 2013).

Graphical information and the context of the mapping medium used may also influence the users' interpretation of symbols. Keil et al. (2019) noticed that when identifying your current position, you should identify landmarks in the area and relate them to the appropriate point symbols on the map. In many cases, the design of distinctive symbols was not based on the visual characteristics of the represented object, but on redefined design standards related to the function of the object. This fact can make it difficult for map users to interpret landmarks and match them with the representation if the feature or characteristics of the object are not visually visible or if the pictogram is poorly designed (Elias and Paelke 2008). Keil et al. (2019), based on their research, concluded that ambiguous symbols used on the map result in a longer memory of them, which, in consequence, may also have an impact on its weaker interpretation.

Surveying methods in cartography are studied through: directly supervised surveys, tasks performed in the field by means of mobile devices, direct observation of the user, observation with remote saving of the user's movement and eye-tracking observation (Cybulski 2021; Horbiński et al. 2021; Medyńska-Gulij et al. 2020; Cybulski 2020). Collecting data by means of online survey constitutes one of the best methods of obtaining subjective information about users' opinions (Horbiński et al. 2020). Homogenous groups of respondents with the suitable number of users are usually invited to participate in surveys (Wielebski and MedyńskaGulij 2019). In studies devoted to multimedia cartography the number of respondents oscillates between 20 and 100 for surveys on the evaluation of a single map version (Medyńska-Gulij et al. 2020), which increases to the significantly higher number for several map versions (Cybulski and Horbiński 2020; Cybulski 2020).

Video games constitute complex technological systems that combine numerous spatial, physical, and social issues. Geographers and cartographers are dealing with the topic of "cartography and games" (Garfield 2012; Coulton et al. 2017; Edler and Dickmann 2017; Edler 2020) more and more often, describing the technical aspects of game and component production. The discussion about a constantly increasing impact of games on cartographic visualisations manifests itself through increasing popularity of virtual reality and augmented reality environment (Hruby et al. 2019; Büyüksalih et al. 2020; Keil et al. 2020; Walmsley and Kersten 2020; Zagata et al. 2021). The concept of "Game Cartography Interface" is frequently touched upon in articles on games. GCI encompasses a widely understood user interface that depicts a map of the game's world along with additional information elements (symbols, notes, text, notifications, icons) that can be modified or are added to the map through special events during the game (Toups et al. 2019).

Fig. 1 Set of symbols

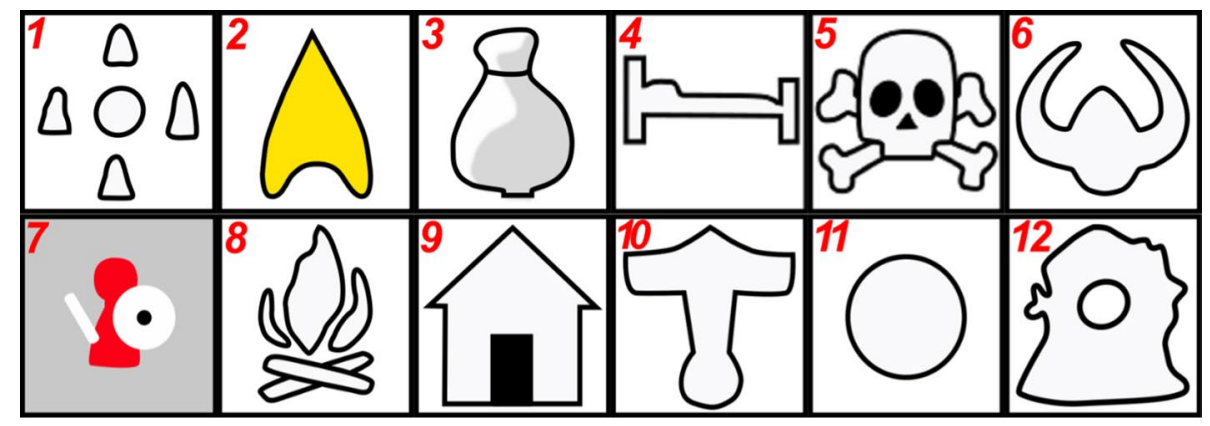




\section{Materials and Methods}

\subsection{Symbols in Valheim}

In Valheim a set of twelve symbols was used (Fig. 1). The set uses the meaning (function) of the symbol in presentation through pictography. Pictographs can be interpreted correctly without prior learning or using the legend (Korpi et al. 2013). Due to this advantage pictographs are usually included in maps for beginners or occasional users, such as tourists (Kostelnick et al. 2008). The authors would also include gamers in this group, as this group of users cannot be overwhelmed with too complicated map symbols. A map is an integral part of each video game (in which it was used), constituting also the navigation element, and it should not be an obstacle to playing the game. The developers of Valheim boosted the level of difficulty in terms of exploring the world of the game by not considering textual explanations to individual symbols used in the map interface. Analysing symbols as a whole, the creators employed top-down mechanisms, i.e. dependence on the environment (other symbols), directing the user's attention towards features of potential importance or suggesting the importance (Yarbus 1967; Wolfe 1994; Connor et al. 2004). They also assumed for the most part that gamers would identify symbols on the basis of their previous experience (Keates 1989).

To raise the probability of finding the symbol quickly, the symbol should be easily distinguishable from other symbols and also from the background (North 2016). The authors of Valheim wanted to suggest the most important symbols by assigning them suitable colours: yellow (symbol 2) and red (symbol 7). The employment of the white colour for all the other elements allowed one to distinguish symbols with colours more effectively. Such strategy made it possible for game developers to use top-down mechanisms that gamers are driven by. Top-down mechanisms direct our attention to significant features of the symbol, such as its colour (Itti and Koch 2001).

The set of 12 symbols can be divided into two groups (Table 1) according to how they are supposed to be manipulated. The first group consists of symbols 1-7 that cannot be added to the map content (symbols 1-3, 6-7) or can be added only through the interaction during the game (4-5), not the interaction directly with the map. The second group includes symbols $8-12$. They can be manipulated freely on the map (the gamer may add them, delete them and add descriptions to them).

\subsubsection{Symbol 1}

Symbol 1 (Fig. 1) presents four stones arranged in a ring, with an altar in the middle. It is one of the crucial symbols on the map during the game. First of all, it is a symbol that gamers can see on the map from the very beginning of the game (apart from their own position-symbol 2 or the position of other gamers-symbol 7). During the game the symbol adopts three fundamental functions:

- it is a place in which the gamer starts the game and which serves as a place of revival when the game character dies until the moment of building a shelter and a bed (symbol 4),

- it is a place of putting trophies from bosses that documents the progress of the game,

- it is also a place of activating one out of five special skills (each for every trophy).

Moreover, the symbol is the central place of our gaming world as it defines its precise centre. The symbol is fixed on the map, it cannot be moved or deleted. There is also no description below (Table 1).
Table 1 Features of individual symbols on the Valheim map $(*$ denotes the plot or the interaction with the game)

\begin{tabular}{lllllll}
\hline Map symbols & Permanent & Mobile & Addable & Deletable & More than once & Description \\
\hline 1 & $\mathrm{X}$ & & & & & \\
2 & & $\mathrm{X}$ & & & & \\
3 & $\mathrm{X}$ & & & & $\mathrm{X}$ & \\
4 & $\mathrm{X}^{*}$ & & $\mathrm{X}^{*}$ & $\mathrm{X}^{*}$ & & \\
5 & $\mathrm{X}^{*}$ & & $\mathrm{X}^{*}$ & & & $\mathrm{X}$ \\
6 & $\mathrm{X}$ & & & $\mathrm{X}$ & $\mathrm{X}$ & $\mathrm{X}$ \\
7 & & $\mathrm{X}$ & $\mathrm{X}$ & $\mathrm{X}$ & $\mathrm{X}$ & $\mathrm{X}$ \\
8 & $\mathrm{X}$ & & $\mathrm{X}$ & $\mathrm{X}$ & $\mathrm{X}$ & $\mathrm{X}$ \\
9 & $\mathrm{X}$ & & $\mathrm{X}$ & $\mathrm{X}$ & $\mathrm{X}$ & $\mathrm{X}$ \\
10 & $\mathrm{X}$ & & $\mathrm{X}$ & $\mathrm{X}$ & $\mathrm{X}$ & $\mathrm{X}$ \\
11 & $\mathrm{X}$ & & $\mathrm{X}$ & $\mathrm{X}$ & $\mathrm{X}$ & $\mathrm{X}$ \\
12 & $\mathrm{X}$ & & & & & \\
\hline
\end{tabular}




\subsubsection{Symbol 2}

Symbol 2 (Fig. 1) represents a yellow arrowhead with a sharp tip. The symbol informs the player about their position on the map (and consequently, about their position in the game). It moves in four directions, and the arrowhead suggests the direction the character is going in (Table 1).

\subsubsection{Symbol 3}

Symbol 3 (Fig. 1) demonstrates a bag. In the game it informs about the location of the Merchant (the only non-player character in the game). The symbol appears on the map along with discovering the Merchant (swimming or walking near him). The gamer, not exploring the space or being in the early stage of the game, may not meet the Merchant (and the symbol). There may be more Merchants in the game (more than one). Symbol 3 cannot be moved or deleted by the gamer on the map, it does not have a description either (Table 1).

\subsubsection{Symbol 4}

Symbol 4 (Fig. 1) represents a Bed. It informs the player about the location of their bed as a place in which the gamer may take a rest (wait the night out, move to the next day of the game). The symbol appears on the map after building a shelter and a bed, and individual assigning it to the character. Each gamer has a different bed. When the bed is assigned, the position of the symbol on the map changes. The symbol cannot be removed from the map (only in cases when the character does not have a bed that is assigned to them) and does not have a description (Table 1). Symbol 4 plays a crucial part for the game, because when the character is assigned to his bed for the first time (and for all the subsequent times), the gamer receives the information, where exactly in the game space, he will appear when he dies.

\subsubsection{Symbol 5}

Symbol 5 (Fig. 1) depicts a skull with two crossed bones. It is a universal symbol of pirates, threat, or death. In Valheim it performs an informative function, informing about the place of the character's last death. It is essential to each player, because when a character dies, he loses his entire equipment that he had on him. The position of the last death allows players to regain their lost equipment. The symbol changes its position along with subsequent deaths of the character. The player cannot remove the symbol from the map. The symbol does not have a description (Table 1).

\subsubsection{Symbol 6}

Symbol 6 (Fig. 1) presents a simplified monster's head (an oval and two horns). It informs about the position of the altar for calling one out of five Bosses in the game. The symbol appears as the new subplots unfold. In the world of the game we find certain information that are crucial to the game by reading stone runes. When we find the appropriate runes in the appropriate land, we unblock the position of one of the altars (Bosses). Each Boss has the same symbol but a different description (name of the Boss) to make the distinction easier. There can be several positions of one Boss (altar) in the game. The player may remove the symbol from the map after, for instance, defeating the Boss. The symbol is a breakpoint of the game as without defeating Bosses the player cannot move on in the game. When one out of five Bosses the player receives a trophy that he puts in sacrifice (Symbol 1) and receive one of the unique super skills.

\subsubsection{Symbol 7}

Symbol 7 (Fig. 1) presents a red, simplified (pawn-like) silhouette of a man wielding a sword and a shield. The symbol informs about the position of the other player or, with the Player versus Player option on, a potential enemy. In the right bottom corner of the map interface it is possible to reveal or hide one's position to other players (Fig. 2). If there is just a single player, the symbol will not appear. The symbol moves along with the position of other players. The maximum number of 10 players may participate in the game, so the player may see up to 9 co-players. To distinguish between players, their nickname is always under their symbol (Table 1).

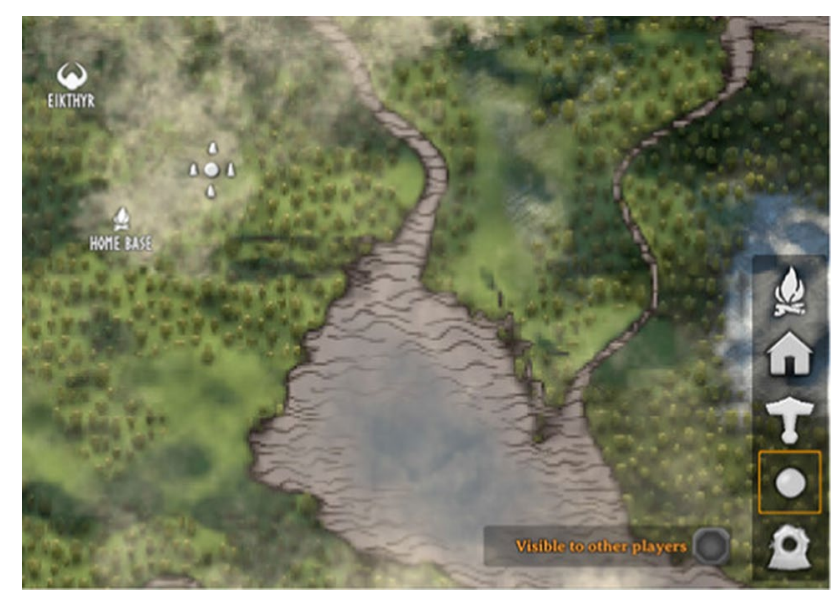

Fig. 2 Fragment of the map from Valheim 


\subsubsection{Symbol 8}

Symbol 8 (Fig. 1), according to the authors of this article, should denote the position of a Bonfire. The Bonfire is an important place in the game as the bed (symbol 4) needs to be located nearby and also meals may be prepared nearby (thus, it determines the standard of living of our character). However, the creators of Valheim offered players an opportunity to subjectively add symbols $8-12$ to the content of the map (Table 1). Hence, the function of the symbol cannot be easily established, because the player can use it to tag anything he wants and add any kind of description to it. Symbols 8-12 can be added (or removed) thanks to the panel located in the bottom right corner of the map interface (Fig. 2).

\subsubsection{Symbol 9}

Symbol 9 (Fig. 1) should, in the authors' opinion, denote the position of the main Shelter in the game.

\subsubsection{Symbol 10}

Symbol 10 (Fig. 1) represents a Hilt of a Sword. In the world of the game it should, according to the authors of the article, denote the position of the forge. The forge plays a significant part in the game, because it helps players create, improve, and fix their equipment (made from metal).

\subsubsection{Symbol 11}

Symbol 11 (Fig. 1), in authors' opinion, represents a Point or a Circle. For this specific symbol one can talk about full subjectivity when it comes to determining its function in the game. The symbol may denote basically anything, from the position of the enemy's camp to the position in which the deposits of natural resources are located.

\subsubsection{Symbol 12}

Symbol 12 (Fig. 1) represents, according to the authors, a Runestone or a Portal. Portals play a significant part in moving around the map. Without them we can cover distances only on foot or by boat. Portals shorten the time needed to cover long distances.

\subsection{Surveys}

Online surveys help researchers determine the level of knowledge and experience of the respondents. This method allows researcher to collect data from a large group of people from any part of the globe, who have access to the Internet.
A digital surveying process secures efficiency and optimal results in terms of collecting data for a database (e.g., Excel) to be analysed afterwards. The authors decided to use the LimeSurvey surveying platform to collect answers (Cybulski and Wielebski 2019; Horbiński et al. 2020). The survey was available on the platform between 19 and 31 March 2021 . A link to our online survey was distributed internationally through gaming-related fora (Reddit, Gamespot, IGN, NeoGAF, Facebook groups) with the opportunity for anyone interested to participate in the survey.

The survey consisted of 16 questions divided into two parts:

- basic information about the respondent and his relations to the game of Valheim,

- questions about opinions on map symbols occurring on the map.

In the first part of the survey users were asked about nationality, age, previous experience in playing Valheim, and how much they had already played if they had some experience. In the second part of the game the user answered the same question for each individual map symbol: in your opinion, what does this symbol mean?

Designing the survey, the authors specified its several features:

- no opportunity to go back to previous questions,

- no opportunity to omit some questions/give the "None" answer,

- the opportunity to fill out the survey just once for a single IP computer,

- unlimited amount of time for answering the questions,

- both open questions and single answer questions were used.

After the survey had been finished, all answers were exported in the.xlsx format for Excel.

\subsection{Group of Respondents}

The number of respondents who participated in the survey was 1043 . To make individual surveys valid, the user had to answer all questions and send the notification about completing the survey. The analysis of answers showed that 352 surveys were incomplete, not meeting the requirements, and they had to be deleted. Out of 691 respondents who filled out the entire survey, the players of Valheim (Gamers) turned out to be the largest group (74.2\%). Posting the survey in social media or on forums allowed the researchers to reach a diverse group of respondents, with Americans (29.1\%) and Poles (19.4\%) as the two dominating nationalities (the survey was filled out by respondents from over 50 


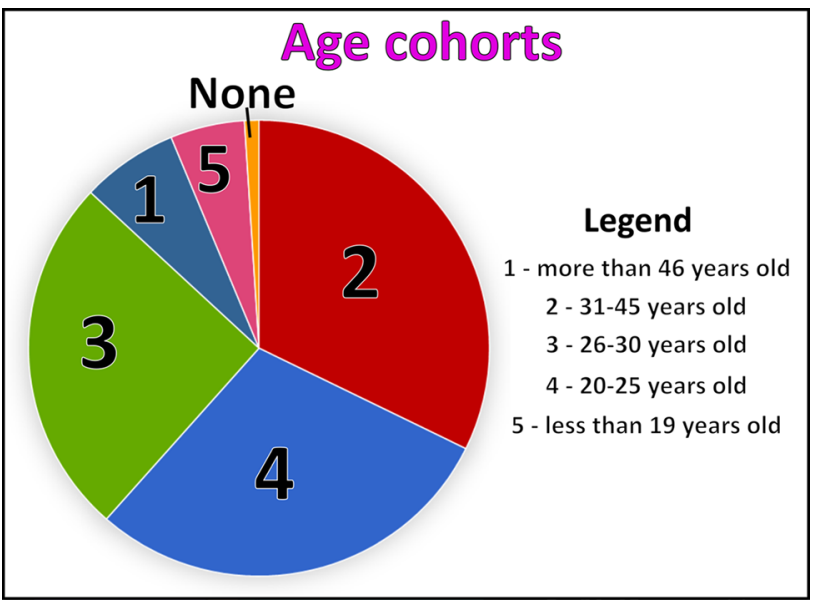

Fig. 3 Group of respondents divided by age

countries). Although the authors expected the survey to be filled out mostly by younger people, the age of respondents was diverse as well (Fig. 3). According to temporal data, respondents had to spend $5 \mathrm{~min}$ on average for the survey (the maximum of $30 \mathrm{~min}$ and a minimum of $1 \mathrm{~min}$ ).

\subsection{Categorisation of Answers}

The data of the unprocessed text of open questions used in surveys are frequently difficult to analyse and laborious. However, the database of the answers is highly valuable due to the fact that the survey does not limit answer opportunities and does not suggest answers to respondents. Using the method of categorisation, the researchers provided answers to open questions (5-16) related to map symbols on the map. All answers to individual questions received their base of categories. Researchers worked out a separate data categorisation for each symbol due to variety of features and meaning. The answers were categorised in relation to the entire group of respondents, without dividing them into players and non-players of Valheim. In order for the answer to be put in a specific category, it had to include at least one word commonly considered acceptable, because otherwise, the answer was categorised as "None". If the respondent gave more than one answer, only the first word, crucial to each question, was taken into consideration. Synonyms, words of similar meaning and words concretised to fit the meaning present in a certain working or professional environment (boat-anchor-harbour) were analysed in terms of one category. After the categorisation had been completed, the number of answers from all categories for each question was analysed and it was determined that the category was to be included in data analysis when the number of answers exceeded the number corresponding to $1 \%$ of all answers in a given group of respondents.

\subsection{Statistical Methods}

To check whether there are statistical differences between the interpretation of symbols by respondents who play and those who do not play Valheim, Pearson's Chi-squared test (with multiple comparisons-the Benjamini-Hochberg Procedure) was done for nonparametric data in the PQStat software (v 1.8.0). For the data that did not meet the Cochran's theorem (i.e. some categories had very few answers), Fisher's exact (dealing with a small sample size in categories) test was additionally done.

\section{Results and Interpretation of Symbols}

\subsection{Interpretation of Symbol 1}

To present the interpretation of individual symbols, it was necessary to demonstrate not only the results for the entire group of respondents but also for the respondents who played Valheim and those who did not separately. The interpretation of Symbol 1 (Fig. 4) for all respondents was based on three categories (1-main spawn-33.9\%; 2-sacrificial altar-30.5\%; 3-standing stones-18.8\%). A significant
Fig. 4 Interpretation of symbol

1

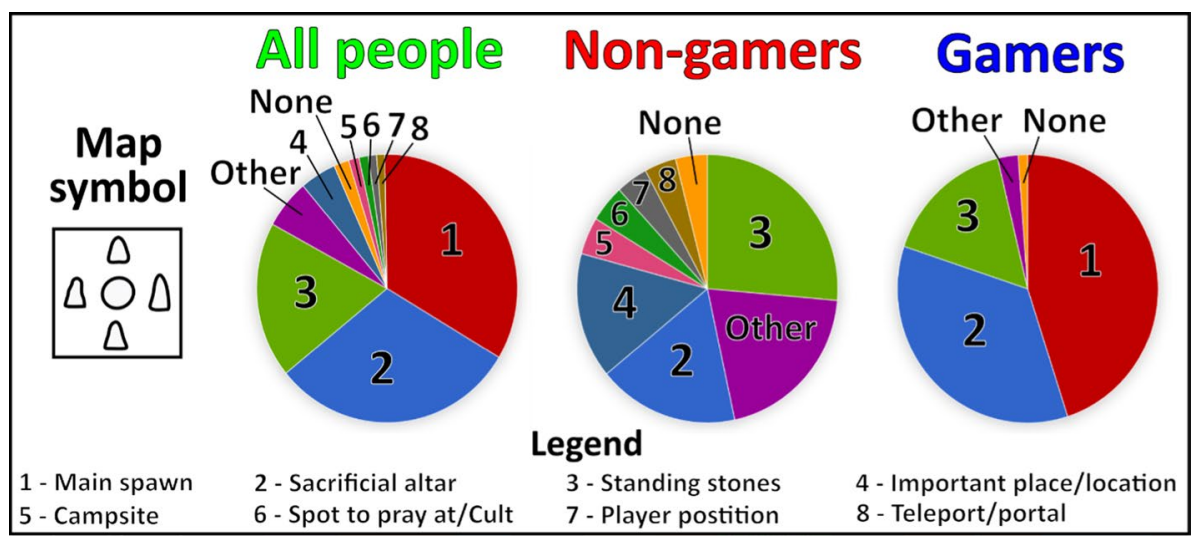


difference between gamers and non-gamers is visible. The difference is verified by Fisher's exact test $(p<0.000001)$. Non-gamers did not consider answer 1 in their answers, which confirms that they had never played Valheim before. They interpreted the symbol literally (3-standings stone26.4\%; 2-sacrificial altar-17.4\%). The Other group (20.2\%) was also an important one, including interpretations of the symbol, such as: sights, compass, wheel, ambush. Gamers were more unanimous, majority of them correctly interpreting the symbol as main spawn (45\%) and sacrificial $\operatorname{altar}(35.1 \%)$

\subsection{Interpretation of Symbol 2}

Symbol 2 (Fig. 5), depicting a yellow arrowhead and informing about the position of the character in the game space, was in most cases interpreted correctly as an icon of the character's position and direction of movement. For all respondents, answer 1 obtained $66 \%$, and answer 2 reached $21.3 \%$. The results for non-gamers are: $44.9 \%$ for answer 1 and $39.9 \%$ for answer 2 . The Other group for non-gamers had $12.9 \%$, with helmet, wind, mouse pointer, and military rank as the most interesting answers. Among gamers, answer 1 dominates $(73.3 \%)$. Answer 3 can be ranked as a fun fact (Star Trek emblem/Spaceship), achieving $2.5 \%$ answers.
Even though the respondents had been well informed, where the symbols were coming from, the association that they had with the symbol resulted in the answer related to a popular science-fiction series, Star Trek.

\subsection{Interpretation of Symbol 3}

Symbol 3 (Fig. 6) refers with its graphics to a bag and in the game informs about the Merchant's position (1-Trader/ Merchant-80.7\%). The symbol has been interpreted correctly by the majority of gamers, which also translates into all respondents (1-Trader/Merchant-62.7\%). Non-gamers gave the large number of diverse answers. It may prove that the symbol of a bag is frequently used and may mean multiple different things. Non-gamers tried to associate this symbol with equipment/items and usually answered that it meant loot/a bag of good (33.1\%) and coin purse/money (25.8\%). The Other group achieved $7.9 \%$, and the most interesting associations were: gift, relic, trash.

\subsection{Interpretation of Symbol 4}

Symbol 4 (Fig. 7) was interpreted in the same way, which resulted from its clarity for the most part. Correct answers were: a bed/sleep and a current spawn point/save point.
Fig. 5 Interpretation of symbol 2

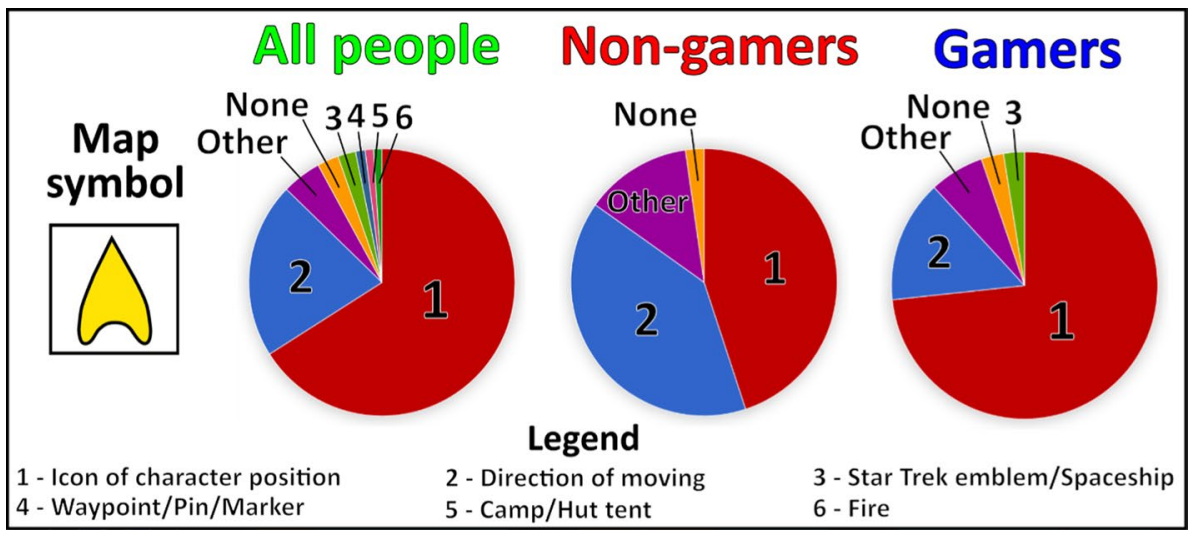

Fig. 6 Interpretation of symbol 3

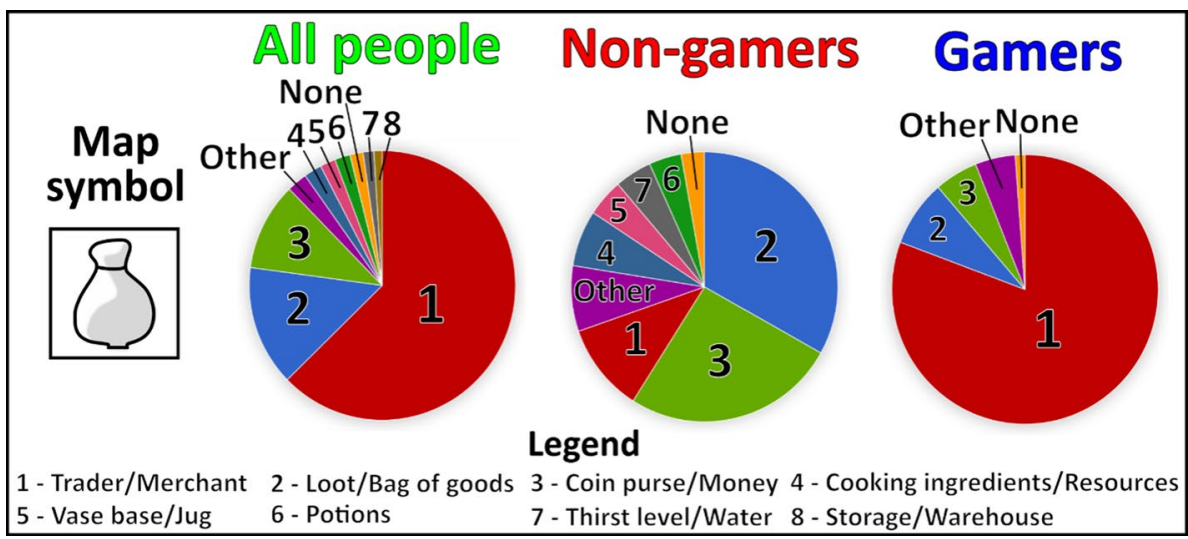


Out of all respondents, 59.8\% chose answer 1 and $33.4 \%$ answer 2 . The majority of non-gamers interpreted symbol 4 as a bed/sleep (76.4\%). It is noteworthy that in this group as much as $11.2 \%$ of respondents interpreted the symbol as hotel/lodging, which resulted from its being used frequently on tourist maps. Answer 1 was chosen by $54 \%$ of gamers, and answer 2 by $42.5 \%$ of them.

\subsection{Interpretation of Symbol 5}

Symbol 5 (Fig. 8), depicting a skull with two crossed bones, informs about the last death of the character. The symbol itself is frequently used for signalling a threat on different chemicals, which translated into the responses by non-gamers, as apart from answer 1 (death location/ Player body-50.6\%) they also often chose answer 2 (danger/caution/do not enter-33.7\%) and answer 4 (posion/ toxic/polluted environment-7.9\%). Gamers chose mostly answer 1 (death location/Player body-91.8\%), which also manifests itself for the entire group of respondents. Interestingly, all respondents decided to interpret the symbol (no None answer).
Fig. 7 Interpretation of symbol 4

Fig. 8 Interpretation of symbol 5

Fig. 9 Interpretation of symbol 6
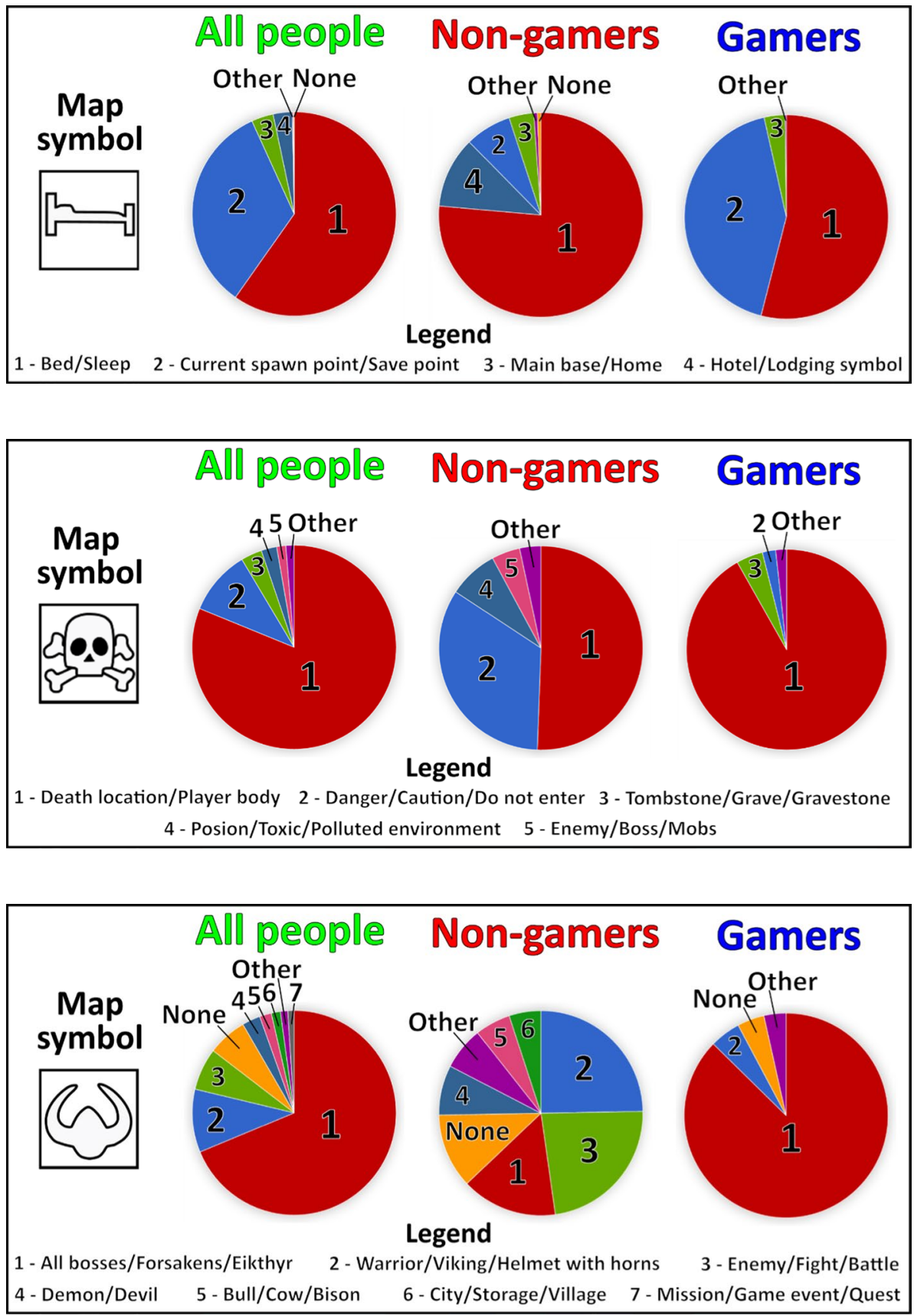


\subsection{Interpretation of Symbol 6}

Symbol 6 (Fig. 9) in Valheim informs about the position of the altar that is used for calling one out of five bosses. Unfortunately, even Valheim players immediately associate the symbol with the enemy (Boss) instead of the place (altar) (1-All bosses/Forsakens/Eikthyr (name of first boss) $-87.3 \%$ ). Many respondents, both gamers (4.9\%) and non-gamers $(24.7 \%)$ associated the symbol with a warrior/ Viking/helmet with horns, which can result from the striking resemblance to a Viking's helmet. Non-gamers gave the large number of different answers, which proves how difficult it was for them to interpret the symbol. The answers they gave were diverse, from a demon/devil (7.9\%) to associations with animals, such as a bull/cow/bison (5.6\%). Many non-gamers (11.8\%), struggling to come up with the interpretation, failed to give any answer whatsoever.

\subsection{Interpretation of Symbol 7}

Symbol 7 (Fig. 10) in the game represents another gamer or a potential enemy. It was correctly interpreted by gamers (1-another player/friend/enemy player-66.9\%). Nongamers used the visual aspects of the symbol to try to explain its meaning (2-shield/defense/armor/solider-36.5\%) or were influenced by the red colour, interpreting the symbol as a form of a fight (4-arena/fight/combat/battle-23.6\%). Many respondents failed to give an answer (none-8\%). The explanation for gamers may be that they may never actually see the symbol, playing in the first-person mode.

\subsection{Interpretation of Symbol 8}

Symbol 8 (Fig. 11) may be associated with a bonfire and was interpreted as such by $43.6 \%$ of all respondents (1-Campfier/Bonfire/Fireplace). A bonfire plays a significant part in the game, not only as a place of preparing meals but also as a form of a camp, where gamers may hide (2-Outpost) Camp/Safe Zone-30.5\%) or warm themselves (3-Firel Warm up-15.2\%). Warming oneself is a decisive factor in survival in some lands in the game. The distribution of answers by gamers and non-gamers slightly diverts from the expected values for the Pearson's Chi-squared test ( $p<0.0005$ - the Cochran's theorem was met). It also confirms the lack of statistical importance for these categories in multiple comparisons by Benjamini-Hochberg. Among gamers, a group of answers appeared that confirmed the function that game developers introduced for the symbol. Gamers (5.5\%) answered that Symbol 8 denotes POI/Map marker, which may prove that an approach to the symbol is subjective, which manifests itself through adding a suitable description to the symbol. Surprisingly, as much as $5.3 \%$ of
Fig. 10 Interpretation of symbol 7
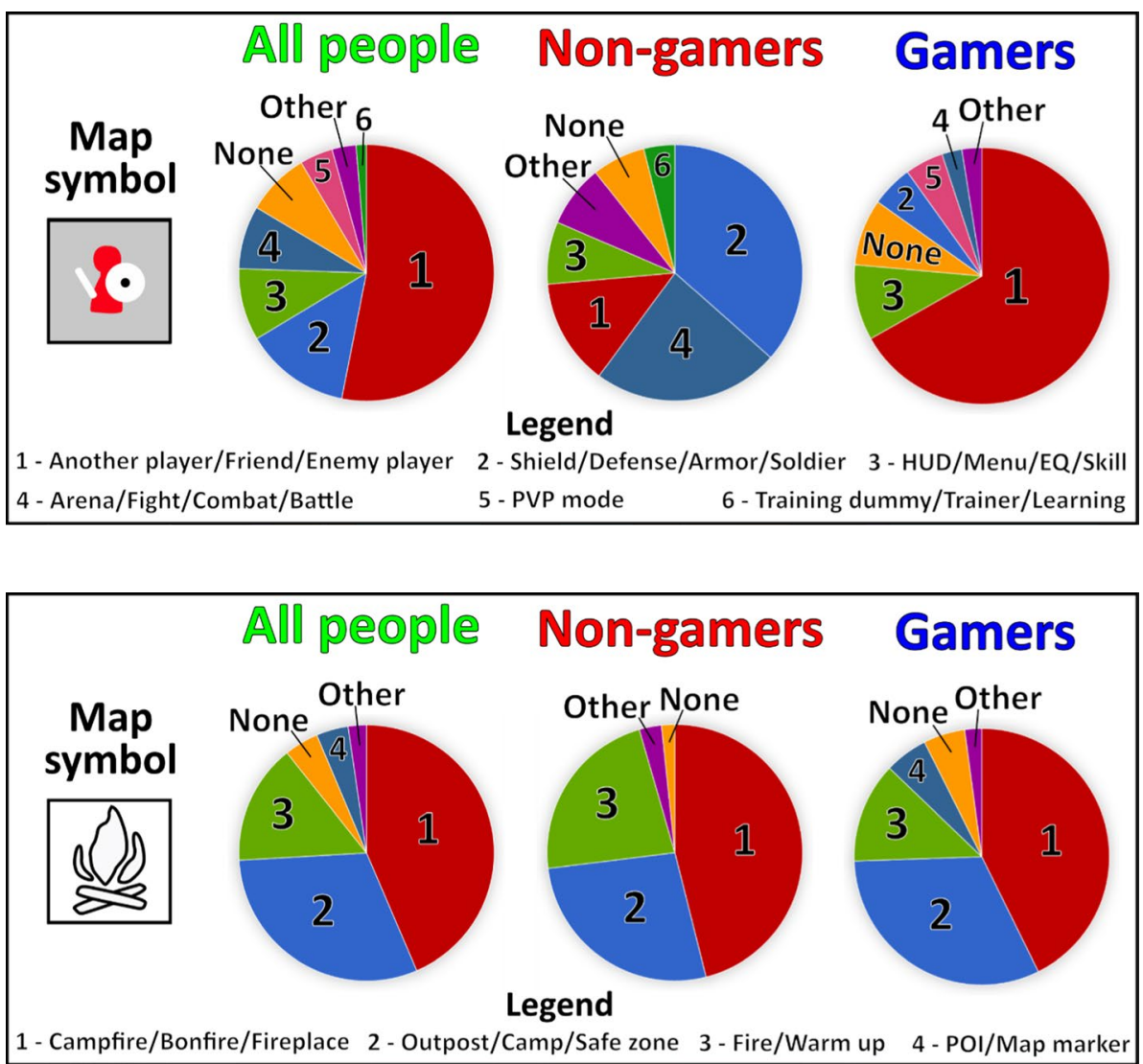
Fig. 12 Interpretation of symbol 9

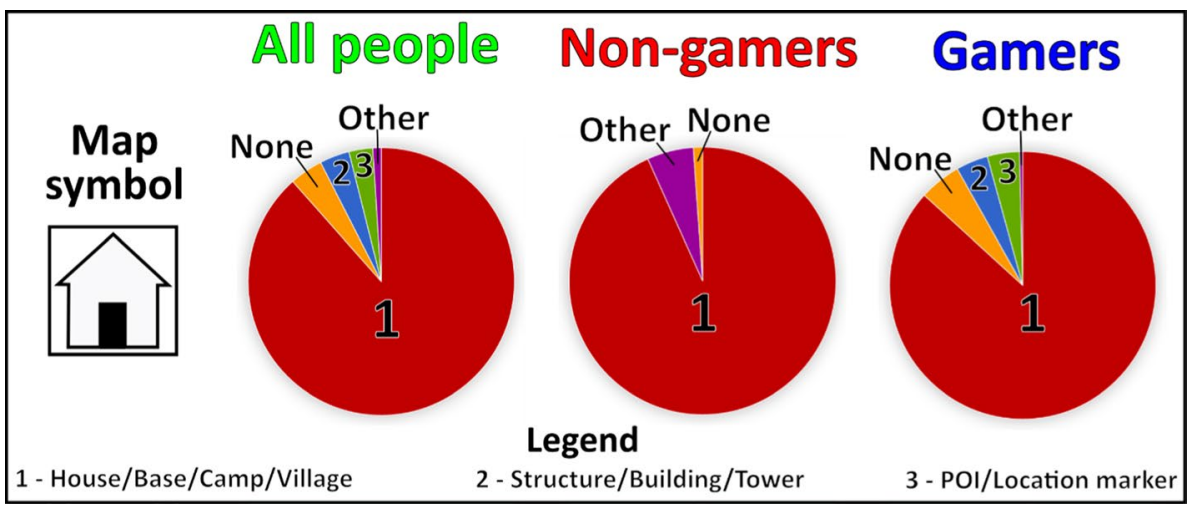

gamers failed to answer the question, which may be partially related to subjectivity in adding the symbol to a map without the explanation of how it functions in the game.

\subsection{Interpretation of Symbol 9}

The group of respondents basically agreed on Symbol 9 (Fig. 12) despite the function introduced by game developers that allows gamers to add subjective position and description to this symbol. The symbol was interpreted as a house/base/ camp/village (88.4\%).

\subsection{Interpretation of Symbol 10}

Symbol 10 (Fig. 13), depicting a hilt of a sword, was interpreted by respondents in many different ways. The largest group consisted of those who did not even try to interpret the symbol (19.7\%). It was interpreted as a sword hilt only by $1.2 \%$ of respondents, which proves how difficult it was to interpret. Gamers usually referred to their choices from the game, indicating that the symbol may be used for anything and the description will help distinguish whether it is a building/point/place (1-POI/Waypoint-18.9\%). Other answers depended heavily on what places gamers used this symbol for. Groups 2, 3, 4, 5, 8, 9 belong to such answers. Some respondents, by deduction (the game refers to Nordic mythology), managed to find a link between a symbol and Mjolnir, a mythical hammer of god Thor (7.8\%), or just with any kind of weapon (7-gamers-2.9\%, non-gamers-11.8\%). Group 12 (Plane/Airport-7.3\%), i.e. associations provided by non-gamers, were particularly interesting, with tips, health or eagle as the most interesting ones, and Other being a very frequent answer (24.7\%).

\subsection{Interpretation of Symbol 11}

Symbol 11 (Fig. 14), although visually simple, had many interesting interpretations. The most answers referred to possible subjective meaning of the symbol (1-POI/ Waypoint-40.2\%), just as in the case of the symbols previously discussed. Interestingly, the answers were given also by non-gamers $(16.9 \%)$, which may prove that that symbol is universal. Like for symbol 10, numerous respondents failed to give the answer (12.9\%). It surprises the authors as the symbol is not difficult for interpretation. For this symbol, many gamers also provided references that they themselves used in the game $(2-19.5 \%$; $3-7.8 \%$;
Fig. 13 Interpretation of symbol 10

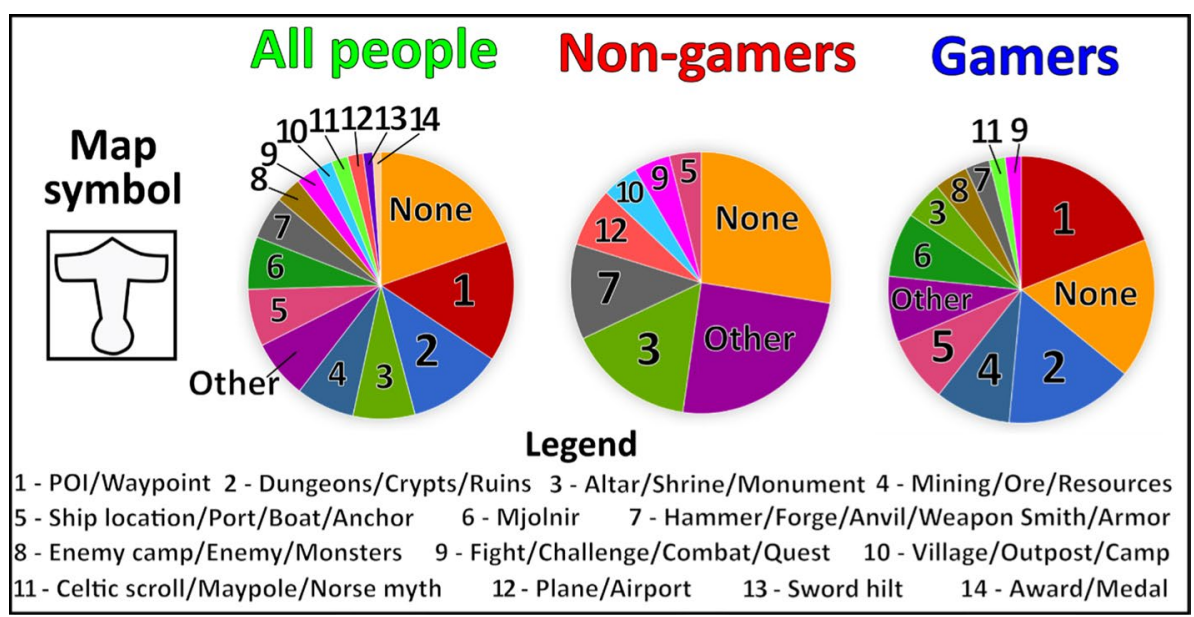


Fig. 14 Interpretation of symbol 11

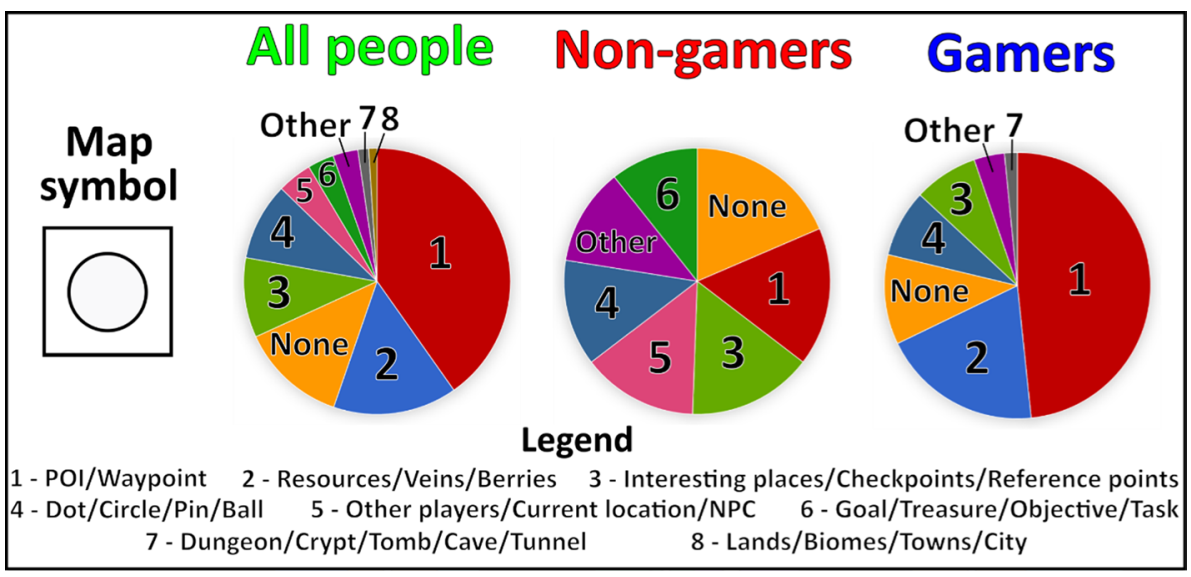

7-1.6\%). Non-gamers employed their knowledge from other games, in which the symbol was used to represent other gamers, NPC (5-14\%), some objects or tasks to be completed $(6-10.7 \%)$. Both gamers $(8.2 \%)$ and nongamers $(12,9 \%)$ attempted to interpret the symbol, literally as a dot, circle, pin or a ball. When it comes to Other answers, a hole, table, pool, stop are the most interesting.

\subsection{Interpretation of Symbol 12}

Symbol 12 (Fig. 15) refers to a portal or runes, and this is how it was interpreted by both gamers (1-50.5\%; 3-4.7\%) and non-gamers $(1-7.9 \% ; 3-5.6 \%)$. Like for Symbols 10 and 11, answers POI/Map marker (5.3\%) appeared among gamers but there were not so many of them. Again, a large group of respondents (both gamers and non-gamers) failed to answer the question (19.7\%). Apart from typical associations with games $(2-6.7 \%, 5-7.3 \%$; 9-3.9\%), non-gamers interpreted the symbol in a very interesting way (e. g. fish face/fish/animal-5.6\% and ghost/witch's house-6.2\%), with some interesting answers from the Other group, such as a toilet, hunger level, shop.

\section{Conclusions and Discussion}

Video games are more and more present in our lives, with hundreds of millions of gamers playing them every day (Hendrikx et al. 2012). Usually, video games employ symbols presented by pictography to inform users about the game. As Korpi et al. (2013) note, such symbols can be interpreted correctly without prior learning or using the legend. Thus, the authors of the article decided to employ the set of 12 symbols (Fig. 1) from the game of Valheim. The basic objective was to observe differences in interpretation between gamers and non-gamers. Kostelnick et al. (2008) believe that pictographs are supposed to be used by beginners or occasional users, in the group of whom the authors would include gamers as well.

Game developers, when designing symbols as a whole (a group/set), applied top-down mechanisms, i.e. dependence on the environment. In this case, the environment of symbols consists of other symbols. This is how the attention of users is directed towards features of potential importance or those suggesting the meaning of the symbol (Yarbus 1967; Wolfe 1994; Connor et al. 2004). The work of game developers
Fig. 15 Interpretation of symbol 12

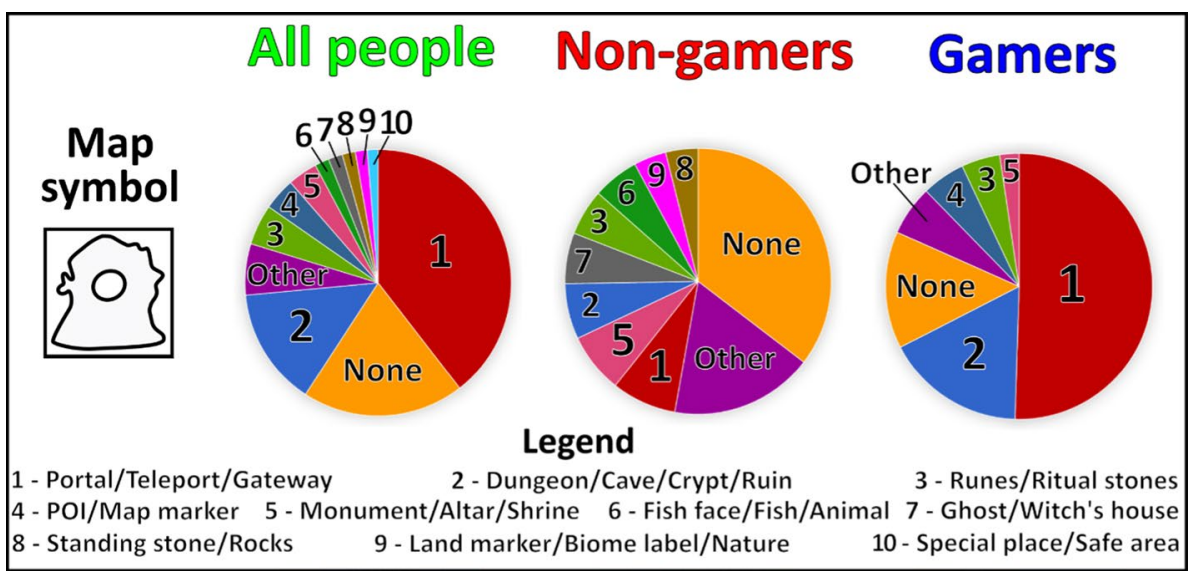


(the beta version) was to a large extent based on previously gained knowledge and experience of gamers.

The employment of bottom-up mechanisms (Itti and Koch 2001), such as assigning two colours to symbols (yellowsymbol 2, red-symbol 7), is evaluated negatively by the authors. First of all, the yellow colour introduced a little chaos when it comes to reception by gamers, namely, they interpreted the colour as a Star Trek emblem (2.5\% answers). The red colour, which quite suggestively informs gamers about a threat or a potential fight, was used to inform about other gamers. To a large extent, the game is based on teamwork, the minimisation of effort needed to, for instance, collect building materials, or divided exploration of the game's world. Hence, the colour that has such negative connotations should not be used to inform about other gamers. The authors suggest the employment of this colour only with the $\mathrm{PvP}$ (Player versus Player) mode on.

Based on the research results, the authors see some recommendations for the future design and use of symbols in video games. First, they recommend using a color to distinguish a symbol from other symbols. The players' experience and knowledge of given symbols or their sets should be used with particular emphasis. Symbols that are widely used in everyday life should also be used in video games. Simple symbols such as symbol 11 (Fig. 11) create many groups of responses among users; therefore, the authors suggest the use of more graphically complex symbols, but still easy to identify.

Answering the research questions asked in the introduction, the authors believe that the majority of respondents who play Valheim can interpret the symbols correctly. For the more complex symbols, such as Symbol 11, both gamers and non-gamers have problems with interpretation, which results from the ambiguity of the symbol and a subjective decision to assign the meaning to the symbol during the game. Non-gamers had actually the greatest problem with interpreting symbols related to the game that had the meaning other than what the symbol would suggest. Just like in the case of Symbol 1, none of respondents determined its meaning as a main spawn. On the one hand, it confirms that the group had not played the game before and that the symbol itself, apart from a direct symbol-place translation, had also a different meaning/function in the game. Many respondents, both gamers and non-gamers, heavily relied on their experience and knowledge (game- or life-based), which resulted in their interpretation not always being correct.

Symbols 8-12 were designed by developers of Valheim to be assigned meaning or function by gamers. Analysing the surveys, one can easily note that only 10 respondents interpreted the symbol as POI.
The authors believe that in the current situation in the world online surveys posted on the Internet constitute the best solution for collecting information from large groups of people dispersed all around the globe. In the process of creating a survey based on subjective answers of respondents the online method contributed to a significant facilitation in terms of collecting and processing textual data (Cybulski and Wielebski 2019; Horbiński et al. 2020). The authors do not exclude narrowing the pool of questions down to single answer questions, with previously worked out examples due to the amount of work with the categorisation of answers.

Statistical tests, conducted by means of the Pearson's Chisquared test and Fisher's exact test (with the Cochran's theorem not being met) showed $p$ value $<0.000001$. The significance tells us only that there are some differences in values between gamers and non-gamers, and their interpretation of symbols. However, it cannot answer the question whether or not the differences are consistent with the hypothesis presented. Therefore, the authors' conclusions were based, for the most part, on absolute values that either verified or disproved their observations.

In the future, the research on the interpretation of different map symbols, not only in video games but also in all cartographic products, is worth continuing. As this study shows, there are unlimited opportunities to combine games and cartography in the form of academic research. Along with every new title on the market a plethora of new opportunities regarding research the authors appear. The authors hope that this article will be only a germ of their academic work intended to combine video games and cartography.

Acknowledgements This paper is the result of research on visualization methods carried out within statutory research in the Department of Cartography and Geomatics, Faculty of Geographical and Geological Sciences, Adam Mickiewicz University Poznań, Poland.

Funding This research received no external funding.

\section{Declarations}

Conflict of interest The authors declare no conflict of interest.

Open Access This article is licensed under a Creative Commons Attribution 4.0 International License, which permits use, sharing, adaptation, distribution and reproduction in any medium or format, as long as you give appropriate credit to the original author(s) and the source, provide a link to the Creative Commons licence, and indicate if changes were made. The images or other third party material in this article are included in the article's Creative Commons licence, unless indicated otherwise in a credit line to the material. If material is not included in the article's Creative Commons licence and your intended use is not permitted by statutory regulation or exceeds the permitted use, you will need to obtain permission directly from the copyright holder. To view a copy of this licence, visit http://creativecommons.org/licenses/by/4.0/. 


\section{References}

Bertin J (1974) Graphische semiologie: diagramme, netze, karten. Walter de Gruyter, Berlin

Bertin J (1983) Semiology of graphics: diagrams, networks, maps, trans. W. Berg. University of Wisconsin Press, Madison

Burigat S, Chittaro L (2008) Decluttering of icons based on aggregation in mobile maps. In: Meng L, Zipf A, Winter S (eds) Mapbased mobile services design interaction and usability. Springer, Berlin, pp 13-32

Büyüksalih G, Kan T, Özkan GE, Meriç M, Isın L, Kersten TP (2020) Preserving the knowledge of the past through virtual visits: from 3D laser scanning to virtual reality visualisation at the Istanbul Çatalca İnceğiz Caves. PFG J Photogr Remote Sens Geo-Information Sci. https://doi.org/10.1007/s41064-020-00091-3

Connor CE, Egeth HE, Yantis S (2004) Visual attention: bottom-up versus top-down. Curr Biol 14(19):R850-R852. https://doi.org/ 10.1016/j.cub.2004.09.041

Coulton P, Huck J, Gradinar A, Salinas L (2017) Mapping the beach beneath the street: digital cartography for the playable city. In: Nijholt A (ed) Playable cities. The city as digital playground. Springer, Singapore, pp 137-162

Cybulski P (2020) Spatial distance and cartographic background complexity in graduated point symbol map reading task. Cartogr Geogr Inf Sci 47(3):244-260. https://doi.org/10.1080/15230406. 2019.1702102

Cybulski P (2021) Effectiveness of memorizing an animated routecomparing satellite and road map differences in the eye-tracking study. ISPRS Int J Geo-Information 10:159. https://doi.org/10. 3390/ijgi10030159

Cybulski P, Horbiński T (2020) User experience in using graphical user interfaces of web maps. ISPRS Int J Geo Inf 9:412. https:// doi.org/10.3390/ijgi9070412

Cybulski P, Wielebski Ł (2019) Effectiveness of dynamic point symbols in quantitative mapping. Cartogr J 56(2):146-160. https:// doi.org/10.1080/00087041.2018.1507183

Edler D (2020) Where spatial visualization meets landscape research and "pinballology": examples of landscape construction in pinball games. KN J Cartogr Geogr Inf 70:55-69. https://doi.org/10.1007/ s42489-020-00044-1

Edler D, Dickmann F (2017) The impact of 1980s and 1990s video games on multimedia cartography. Cartogr Int J Geogr Inf Geovisualization 52(2):168-177. https://doi.org/10.3138/cart.52.2.3823

Eide $\varnothing$ (2016) Media boundaries and conceptual modelling: between texts and maps. Palgrave Macmillan, London

Elias B, Paelke V (2008) User-centered design of landmark visualizations. In: Meng L, Zipf A, Winter S (eds) Map-based mobile services. Lecture notes in geoinformation and cartography. Springer, Berlin. https://doi.org/10.1007/978-3-540-37110-6_3

Garfield S (2012) On the map. Why the world looks the way it does. Profile Books, London

Harley JB (2009) Maps, knowledge, and power. In: Henderson G, Waterstone M (eds) Geographic thought: a praxis perspective. Routledge, London

Hendrikx M, Meijer S, van der Velden J, Iosup A (2012) Procedural game content generation: a survey. ACM Trans Multimed Comput Commun Appl 9(1):24. https://doi.org/10.1145/0000000.0000000

Horbiński T, Cybulski P, Medyńska-Gulij B (2020) Graphic design and placement of buttons in mobile map application. Cartogr $\mathbf{J}$ 57(3):196-208. https://doi.org/10.1080/00087041.2019.1631008

Horbiński T, Cybulski P, Medyńska-Gulij B (2021) Web map effectiveness in the responsive context of the graphical user interface. ISPRS Int J Geo-Informations 10:134. https://doi.org/10.3390/ ijgi10030134
Hruby F, Ressl R, del Valle G (2019) Geovisualization with immersive virtual environments in theory and practice. Int J Digit Earth 12(2):123-136. https://doi.org/10.1080/17538947.2018.1501106

Itti L, Koch C (2001) Computational modelling of visual attention. Nat Rev Neurosci 2(3):194-203. https://doi.org/10.1038/35058500

Keates JS (1989) Cartographic design and production, 2nd edn. Longman, London

Keates JS (1996) Understanding maps, 2nd edn. Longman, Edinburgh Gate

Keil J, Edler D, Dickmann F, Kuchinke L (2019) Meaningfulness of landmark pictograms reduces visual salience and recognition performance. Appl Ergon 75:214-220. https://doi.org/10.1016/j. apergo.2018.10.008

Keil J, Korte A, Ratmer A, Edler D, Dickmann F (2020) Augmented reality (AR) and spatial cognition: efects of holographic grids on distance estimation and location memory in a 3D indoor scenario. PFG J Photogramm Remote Sens Geoinf Sci. https://doi.org/10. 1007/s41064-020-00104-1

Korpi J, Haybatollahi M, Ahonen-Rainio P (2013) Identification of partially occluded map symbols. Cartogr Perspect. https://doi.org/ 10.14714/CP76.59

Kosslyn SM, Koenig O (1992) Wet mind: the new cognitive neuroscience. Maxwell Macmillan, Toronto

Kostelnick JC, Dobson JE, Egbert SL, Dunbar MD (2008) Cartographic symbols for humanitarian demining. Cartogr J 45(1): 18 31. https://doi.org/10.1179/000870408X276585

Langer SK (1953) Feeling and form: a theory of art. Charles Scribner's Sons, New York

Lloyd R (1997) Visual search processes used in map reading. Cartographica 34(1):11-32. https://doi.org/10.3138/ F342-1217-827R-0777

MacEachren AM (1995) How maps work: representation, visualization and design. Guilford Press, New York

Medyńska-Gulij B, Zagata K (2020) Experts and gamers on immersion into reconstructed strongholds. ISPRS Int J Geo-Information 9:655. https://doi.org/10.3390/ijgi9110655

Medyńska-Gulij B, Wielebski Ł, Halik Ł, Smaczyński M (2020) Complexity level of people gathering presentation on an animated map-objective effectiveness versus expert opinion. ISPRS Int J Geo-Information 9(2):117. https://doi.org/10.3390/ijgi9020117

North H (2016) Designing better symbols: an attentional approach to match symbols to performance goals. Open access master's thesis, Michigan Technological University. Doi: https://doi.org/10.37099/ mtu.dc.etdr/151

Thompson MA, Lindsay JM, Gaillard J (2015) The influence of probabilistic volcanic hazard map properties on hazard communication. J Appl Volcanol. https://doi.org/10.1186/s13617-015-0023-0

Toups ZO, Lalone N, Alharthi SA, Sharma HN, Webb AM (2019) Making maps available for play: analyzing the design of game cartography interfaces. ACM Trans Comput Hum Interact 26(5):146. https://doi.org/10.1145/3336144

Toups ZO, Lalone N, Spiel K, Hamilton B (2020) Paper to pixels: a chronicle of map interfaces in games. In Proceedings of the 2020 ACM designing interactive systems conference. association for computing machinery, New York, NY, USA. pp, 1433-1451. Doi: https://doi.org/10.1145/3357236.3395502

Treisman A, Gelade G (1980) A feature-integration theory of attention. Cogn Psychol 12(1):97-136. https://doi.org/10.1016/00100285(80)90005-5

Walmsley A, Kersten TP (2020) The Imperial Cathedral in Königslutter (Germany) as an immersive experience in virtual reality with integrated $360^{\circ}$ panoramic photography. Appl Sci 10(4):1517. https://doi.org/10.3390/app10041517

Werner PA (2017) Augmented reality and perception of analogue and digital images and maps. Proceedings 1:56. https://doi.org/10. 3390/IS4SI-2017-03923 
Wielebski Ł, Medyńska-Gulij B (2019) Graphically supported evaluation of mapping techniques used in presenting spatial accessibility. Cartogr Geogr Inf Sci 46(4):311-333. https://doi.org/10.1080/ 15230406.2018.1479311

Wolfe JM (1994) Guided search 2.0 a revised model of visual search. Psychon Bull Rev 1(2):202-238. https://doi.org/10.3758/BF032 00774

Wolfe JM (2007) Guided search 4.0: current progress with a model of visual search. In: Grey W (ed) Integrated models of cognitive systems. Oxford, New York, pp 99-119
Wolfe JM, Horowitz TS (2004) What attributes guide the deployment of visual attention and how do they do it? Nat Rev Neurosci 5:1-7. https://doi.org/10.1038/nrn1411

Yarbus AL (1967) Eye movements during perception of complex objects. Springer, USA

Zagata K, Gulij J, Halik Ł, Medyńska-Gulij B (2021) Mini-map for gamers who walk and teleport in a virtual stronghold. ISPRS Int J Geo-Information 10:96. https://doi.org/10.3390/ijgi10020096 